\title{
Evidence for Maternal Style Among Adult Female Dolphins When Sharing Pectoral Fin Contacts with Their Calves
}

\author{
Kathleen M. Dudzinski1 ${ }^{*}$, Christine A. Ribic ${ }^{2}$, Heather M. Manitzas Hill ${ }^{3}$, \& Teresa T. Bolton ${ }^{4}$ \\ ${ }^{1}$ Dolphin Communication Project, Port Saint Lucie, Florida \\ ${ }^{2}$ U.S. Geological Survey, Wisconsin Cooperative Wildlife Research Unit, Department of Forest and Wildlife Ecology, University \\ of Wisconsin, Madison, Wisconsin \\ ${ }^{3}$ Psychology Department, St. Mary's University, San Antonio, Texas \\ ${ }^{4}$ The Roatan Institute for Marine Sciences, Anthony's Key Resort, Sandy Bay, Roatan, Honduras \\ *Corresponding author (Email: kathleen@dcpmail.org)
}

Citation - Dudzinski, K. M., Ribic, C. A., Manitzas Hill, H. M., \& Bolton, T. T. (2021). Evidence for maternal style among adult female dolphins when sharing pectoral fin contacts with their calves. Animal Behavior and Cognition, $8(1)$, 52-68. https://doi.org/10.26451/abc.08.01.05.2021

\begin{abstract}
Adult bottlenose dolphins share pectoral fin contacts (PFC) to manage their social relationships but less is known about how mothers share PFC with their calves. Using a dataset collected over 16 years, we analyzed how 10 matrilines, including three second generation female dolphins in a maternal role, used PFC with their pre-weaned calves. Mothers had different rates of initiation with their calves forming a continuum from those initiating few contacts $(15 \%)$ to those initiating more $(44 \%)$. For mothers with all-aged calves, the lateral side was contacted the most to start interactions with mothers contacting body parts at a similar rate. All mothers assumed the same posture regardless of their role as initiator or receiver, with horizontal the most prevalent posture. Two maternal styles were found for PFC: high and low use of PFC. Within the high PFC group, there was individual variation that was related to calf sex. Even though evidence of maternal style was confirmed in PFC exchanges between adult female dolphins and their calves, the number of PFC shared between these kin was only $9 \%$ of all documented PFC contacts $(N=4,345)$ over 16 years, suggesting that other forms of tactile contact may be more important within the confines of the mother-offspring relationship in delphinids.
\end{abstract}

Keywords - Behavior, Bottlenose dolphins, Mother-calf dyads, Pectoral fin contact, Tactile contact

Most dolphin species are characterized by a fission-fusion social structure with smaller subgroups mingling and merging to form larger groups to forage or socialize and then dividing into smaller groups of same or different membership. Within these fluid societies, dolphins maintain complex relationships (Connor, 1992; Lusseau, 2003; Lusseau et al., 2006; Smolker et al., 1992). In some coastal delphinid populations, adult male Indo-Pacific bottlenose dolphins (Tursiops aduncus) form relationships that last their lifetimes with associations that rival the strength of the mother/calf bond (Connor et al., 1992). These male friendships facilitate increased breeding success when pairs compete with other male alliances (Connor, 1992; Connor et al., 1992; Wells et al., 1987), and alliances have been observed to coordinate their activity in competition with other male alliances for reproductive success (Connor, Smolker, et al., 2006). Some alliances can vary in duration, size, and stability, though first order alliances may persist for 20 years or more (Connor \& Krützen, 2015). Young males will engage in much social-sexual activity, with pectoral fin contact (Dudzinski \& Ribic, 2017) used as a social bonding tool that facilitates establishing and maintaining strong associations between individuals - this is a stage when young dolphins cultivate their social relationships and practice their social skills (Stanton \& Mann, 2012). As adults, female dolphins coordinate with other adult females for a variety of reasons and have been recorded, in some groups, to babysit other females' calves (Dudzinski, 1996; Mann \& Smuts, 1998), to coordinate behavior to fend off 
harassment by adult males (Smolker et al., 1992), to develop foraging techniques and skills (Mann et al., 2007; Sargeant \& Mann, 2009), and to protect calves (Mann et al., 2000). Still, one of the strongest bonds among dolphins is between a mother and her calf (e.g., Gubbins et al., 1999; Mann et al., 2000; Mann \& Smuts, 1999).

Dolphin calves of most species are reared by their mothers for two to four years on average. The mother-calf bond is critical for survival and future social network success (Gibson \& Mann, 2008). Calves depend on their mothers for protection, nutrition, resting opportunities, energy savings, and comfort or security (Mann et al., 2000; Mann \& Smuts, 1999). Calves learn how to forage and navigate social networks from their mothers during their first few years of life (Gibson \& Mann, 2008; Krzyszczyk et al., 2017). Even after weaning, juvenile dolphins may maintain their associations with their mother's social group until they form their own social group(s); when they become reproductively mature, females rejoin their natal pods and males begin to roam as dyads within and between larger networks (Mann et al., 2000; Mann \& Smuts, 1999).

Dolphins in managed care demonstrate the same behavioral milestones and maternal care as wild dolphins (Gubbins et al., 1999; Hill et al., 2007). Mothers maintain continuous vigilance of their calves, especially early during the first year of life (Hill et al., 2008; Lyamin et al., 2005, 2007, 2008). Vigilance is monitored both visually and tactically by mothers but to different degrees; some mothers are extremely vigilant and protective of their calves, monitoring their calf's behavior by keeping the calf in close proximity and immediately retrieving a calf that has strayed too far, which may involve directed trajectory changes, including pushing or tossing the calf into the desired swim path (Hill et al., 2007). Many of these highly vigilant mothers were also more likely to discipline their calves for separations and, in some cases, exploration (Hill et al., 2007). In contrast, other mothers were more relaxed and allowed their calves to travel greater distances from her for longer periods, without frequent discipline (Hill et al., 2007). These quantitative and qualitative differences comprise evidence for different maternal styles. One area that has not been explored fully for dolphins is the role of contact in maternal styles. (Note: use of the word contact without a clarifying adjective will refer to any form of physical contact.) Although contact was a behavior that appeared to differ among mother-calf pairs, it was not systematically measured when maternal styles were investigated in these previous studies. Research with beluga (Delphinaptera leucas) calves has shown evidence for individual maternal styles (Hill, 2009; Hill et al., 2013), and contact between beluga mothers and calves was confirmed to significantly contribute to their bond formation (Hill et al., 2018). Still, the limited beluga sample size did not address if individual mother-calf pairs engaged in different types and amounts of contact (Hill et al., 2018), and it remains unclear if contact varies based on maternal style in odontocetes.

Dolphins use tactile contact for both affiliative and agonistic reasons. Within dolphin dyads, physical contact has been shown to aid in the establishment, maintenance, and management of their relationships (Connor, Mann, et al., 2006; Dudzinski \& Ribic, 2017), to be involved in both object and behavioral play (Greene et al., 2011; Kuczaj \& Eskelinen, 2014; Paulos et al., 2010), and to allow for reconciliation after aggressive interactions (Tamaki et al., 2006) or for reconciliation more generally (Weaver, 2003). Physical contact has also been observed as a disciplinary action (Dudzinski, 1998; Hill et al., 2007), a perceived comforting action toward a conspecific (Dudzinski, 1998; Weaver, 2003), an affiliative action (Dudzinski, 1998; Harvey et al., 2017), and in more severe exchanges, contact has been recorded during aggressive interactions (e.g., rostrum rams, fluke kicks, etc., Dudzinski, 1998; Harvey et al., 2017). Although much has been examined with respect to how dolphins share physical contact, there is a paucity of data with regards to how touch (rubbing or static contact) is shared between mothers and their pre-weaned calves.

\section{Current Study Objectives}

We addressed two questions in this study: 1) How do adult female dolphins use pectoral fin contact with their calves? And, 2) are there individual differences among adult female dolphins (i.e., maternal style) in their use of pectoral fin contact, specifically with regards to younger and older calves and with regards to sex of the calves? To address these research questions, we examined the following variables from a 16-year 
archive of video data collected using a focal follow sample protocol with all occurrence documentation of dolphin interactions and behavior, and event sampling of pectoral fin contacts (PFC) exchanged between two individuals from all video data. Previous research focused on PFC exchanges between dolphins in different settings (Dudzinski et al., 2009, 2010, 2013), PFC exchanges as compared with self-contact by individual dolphins (Dudzinski et al., 2012), and PFC as a tool for social bonding between non-kin (Dudzinski \& Ribic, 2017); mother/calf pairs and sibling pairs are the final dyads in this dataset to examine with respect to the potential functional significance of PFC exchanges. To understand how kin might use PFC, we examined adult females as initiators of PFC with their calves, looking at variability by calf age and sex, as well as adult and calf postures and body parts contacted.

\section{Method}

We used data collected on 10 matrilines, including three second-generation females, to facilitate a multi-level examination into how adult females interact using PFC with their calves. Data specific to mothercalf interactions are part of long-term, comparative research into dolphin behavior by the Dolphin Communication Project (DCP; e.g., Dudzinski et al., 2009, 2010; Dudzinski \& Ribic, 2017; Evans-Wilent \& Dudzinski, 2013; Paulos et al., 2007). Permission to observe and collect data on the dolphins at The Roatan Institute for Marine Sciences (RIMS), Anthony's Key Resort (AKR), Roatan, Honduras, was granted by the facility; RIMS holds current permits from the Honduran government for housing dolphins.

\section{Study Site and Population}

Data were collected at RIMS annually for 16 years ( 140 hr inclusive from 2003 to 2018, see Appendix). This common bottlenose dolphin (Tursiops truncatus) group is housed in coastal sea pens adjacent to Bailey's Key, along the NW side of Roatan. The sea pen, located inside Roatan's fringing reef, includes one large enclosure $\left(\sim 8,000 \mathrm{~m}^{2}\right.$ in surface area) and several smaller areas for training, research, and medical procedures. Video data were collected in the large enclosure. Dolphin ages in this study population ranged from neonate to 40+ years; the general social dynamic was similar to that observed for wild bottlenose dolphins (e.g., Connor, Smolker, et al., 2006; Kogi et al., 2004). The total number of dolphins per observation session varied depending on coordination with other facilities managed by RIMS, as well as by recorded deaths and births. Each adult female had a range of one to six offspring over the 16 years of observation (Table 1).

\section{Data Collection}

Dyadic interactions between dolphins and general dolphin behavior were recorded on video with concurrent stereo audio via a mobile video/acoustic system while underwater (Dudzinski et al., 1995). PFC exchanges were event sampled from video data that were collected using an all occurrence focal follow protocol; see Dudzinski et al. (2009) and Dudzinski and Ribic (2017) for details related to video data collection protocols. Each contact between one dolphin's pectoral fin and another dolphin's body (including the pectoral fin) was documented (see Dudzinski et al. (2009) for definitions and sampling protocol); for this study, focus was on mother/calf interactions.

\section{Definitions}

Because this paper extends our examination of PFC exchanges specifically to mother/calf dyads, our definitions for several terms (e.g., body parts, postures) were consistent with previously published work (e.g., Dudzinski et al., 2009, 2010, 2012, 2013; Dudzinski \& Ribic, 2017). Kin relations were assessed based on maternal relatedness; paternity was being assessed via DNA sampling but was not complete for all dolphins in this study group and, thus, paternity was not used to define kin relations.

Four dolphin age classes [i.e., adult ( $2 \mathrm{~m}$ long), subadult ( $3 / 4$ length of adult with less girth), juvenile ( $\sim 1 / 2$ adult length) and calf (less than $1 / 2$ length of adult)] were used to categorize dolphins at RIMS 
and were based on knowledge of year born (from RIMS records) or age estimation if wild-caught based on size and girth in comparison to literature for other bottlenose dolphin study populations (e.g., Connor, Smolker, et al., 2006; Kogi et al., 2004). Because this study focused on younger and older calves, the calf age class was further subdivided into three separate ages based on years: one-year-old calves (C1), twoyear-old calves (C2), and three-year-old calves (C3). For all calves included in this study, date of birth was known. Thus, each calf was assigned to their age class category $(\mathrm{C} 1, \mathrm{C} 2, \mathrm{C} 3)$ for each data collection session based on their birth date (Table 1).

The dolphin body was divided into 11 sections (see Dudzinski et al., 2009) to characterize where on the body contact was made between one dolphin's pectoral fin and another dolphin's body. For this examination of mother-calf exchanges, because there were few contacts for some body parts, those body parts were put into a single category for analyses (Figure 1).

Table 1

Matrilines with Identified Offspring (calves) Available for Observation Across all Years (2003-2018) and the Number of Documented Pectoral Fin Contact Exchanges for Each Mother/calf Pair

\begin{tabular}{|c|c|c|c|}
\hline Mother & Calf name (sex) & Calf ages observed & $\begin{array}{c}\text { Pectoral fin contact exchanges } \\
\text { observed (regardless of Initiator) }\end{array}$ \\
\hline \multirow{5}{*}{ Alita } & Fiona $(\mathrm{F})$ & $\mathrm{C} 1, \mathrm{C} 2, \mathrm{C} 3, \mathrm{~J}, \mathrm{~S}$ & $0,14,2,0,0$ \\
\hline & Anthony (M) & $\mathrm{C} 1, \mathrm{C} 2, \mathrm{C} 3, \mathrm{~J}$ & $7,2,0,0$ \\
\hline & Cortez (M) & $\mathrm{C} 1, \mathrm{C} 2, \mathrm{~J}$ & $\mathrm{nv}, 0, \mathrm{nv}$ \\
\hline & Lenca (M) & $\mathrm{C} 2, \mathrm{C} 3, \mathrm{~J}, \mathrm{~S}$ & $1,1,0,0$ \\
\hline & Dory (F) & $\mathrm{C} 1, \mathrm{C} 2$ & 1,30 \\
\hline \multirow[t]{3}{*}{ Bailey* } & Tank & $\mathrm{C} 1$ & 43 \\
\hline & Ritchie (M) & $\mathrm{J}, \mathrm{S}, \mathrm{A}$ & $2,0,0$ \\
\hline & Ken (M) & $\mathrm{C} 1, \mathrm{C} 2, \mathrm{C} 3, \mathrm{~J}, \mathrm{~S}$ & $0,3,1,0,0$ \\
\hline \multirow[t]{4}{*}{ Carmella } & Dixon (M) & $\mathrm{C} 1, \mathrm{C} 2, \mathrm{C} 3, \mathrm{~J}, \mathrm{~S}$ & $0,2,0,0,0$ \\
\hline & Elli (F) & $\mathrm{C} 2, \mathrm{C} 3, \mathrm{~J}$ & $0,0,0$ \\
\hline & $\operatorname{Stan}(\mathrm{M})$ & $\mathrm{C} 1, \mathrm{C} 2$ & 0,2 \\
\hline & Bailey $(\mathrm{F})$ & $\mathrm{C} 1, \mathrm{C} 2, \mathrm{C} 3, \mathrm{~J}, \mathrm{~S}, \mathrm{~A}$ & $0,10,0,2,0,1$ \\
\hline \multirow[t]{2}{*}{ Cedeña } & Pigeon $(\mathrm{F})$ & $\mathrm{C} 1, \mathrm{C} 2, \mathrm{C} 3, \mathrm{~J}$ & $0,22,2,0$ \\
\hline & Calli (F) & $\mathrm{C} 2, \mathrm{C} 3, \mathrm{~J}$ & $2,0, \mathrm{nv}$ \\
\hline \multirow[t]{3}{*}{ GeeGee** } & $\operatorname{Mika}(\mathrm{F})$ & $\mathrm{C} 3, \mathrm{~J}, \mathrm{~S}, \mathrm{~A}$ & $2, \mathrm{nv}, \mathrm{nv}, \mathrm{nv}$ \\
\hline & Maury (F) & $\mathrm{C} 2, \mathrm{C} 3, \mathrm{~J}, \mathrm{~S}, \mathrm{~A}$ & $19,1,1,1,7$ \\
\hline & Jack (M) & $\mathrm{C} 1, \mathrm{C} 2, \mathrm{C} 3, \mathrm{~J}$ & $0,3,23,0$ \\
\hline \multirow[t]{3}{*}{ Gracie } & Luna $(\mathrm{F})$ & $\mathrm{C} 1$ & 20 \\
\hline & Tilly (F) & $\mathrm{C} 1, \mathrm{C} 2, \mathrm{C} 3, \mathrm{~J}, \mathrm{~S}, \mathrm{~A}$ & $0, \mathrm{nv}, 8,5,0,3$ \\
\hline & Shawn (M) & $\mathrm{C} 1, \mathrm{C} 2$ & 3,25 \\
\hline \multirow[t]{2}{*}{ Maury* } & Champ (M) & $\mathrm{C} 2, \mathrm{C} 3, \mathrm{~J}$ & $0,1,0$ \\
\hline & Mickey (M) & $\mathrm{C} 1, \mathrm{C} 2, \mathrm{C} 3, \mathrm{~J}$ & $0,17,0,0$ \\
\hline \multirow[t]{3}{*}{ Mika* } & Poli (F) & $\mathrm{C} 1, \mathrm{C} 2, \mathrm{C} 3, \mathrm{~J}, \mathrm{~S}$ & $\mathrm{nv}, \mathrm{nv}, \mathrm{nv}, 1,0$ \\
\hline & $\operatorname{Mac}(\mathrm{M})$ & $\mathrm{C} 1, \mathrm{C} 2, \mathrm{C} 3, \mathrm{~J}$ & $6,5,0,0$ \\
\hline & French $(\mathrm{M})$ & $\mathrm{C} 1, \mathrm{C} 2, \mathrm{C} 3, \mathrm{~J}, \mathrm{~S}, \mathrm{~A}$ & $8,4,2,0,0,0$ \\
\hline \multirow[t]{3}{*}{ Mrs. B. } & Margarita (F) & $\mathrm{C} 1, \mathrm{C} 2, \mathrm{C} 3, \mathrm{~J}, \mathrm{~S}$ & $8,6,0,2,0$ \\
\hline & Vin $(\mathrm{M})$ & $\mathrm{C} 1, \mathrm{C} 2, \mathrm{C} 3, \mathrm{~J}$ & $0,9,2,0$ \\
\hline & Tela $(\mathrm{F})$ & $\mathrm{J}$ & 0 \\
\hline \multirow[t]{2}{*}{ Rita } & Ronnie (M) & $\mathrm{C} 1, \mathrm{C} 2, \mathrm{C} 3, \mathrm{~J}, \mathrm{~S}, \mathrm{~A}$ & $4,0,0,0, \mathrm{nv}, \mathrm{nv}$ \\
\hline & Osgood (M) & $\mathrm{C} 1$ & 9 \\
\hline
\end{tabular}

Note. Abbreviations are: $\mathrm{C} 1$ is one-year-old calf; $\mathrm{C} 2$ is two-year-old calf; $\mathrm{C} 3$ is three-year-old calf; and $\mathrm{F}=\mathrm{female}, \mathrm{M}=$ male, $\mathrm{A}=$ adult, $\mathrm{S}=$ subadult, $\mathrm{J}=$ juvenile. Use of "nv" indicates no video collected for that calf at that age with mother; mother and calf were not observed or video-recorded together at the calf age indicated. A " 0 " in the Pectoral fin Contact exchanges column indicates the calf at the indicated age was available for observation and was video-recorded with the mother but that no PFC were documented on video. * indicates second generation adult female matrilines. ** GeeGee was present during observations only for Mika as a C3. 


\section{Figure 1}

Diagram Presenting Labeled Body Parts for Analysis

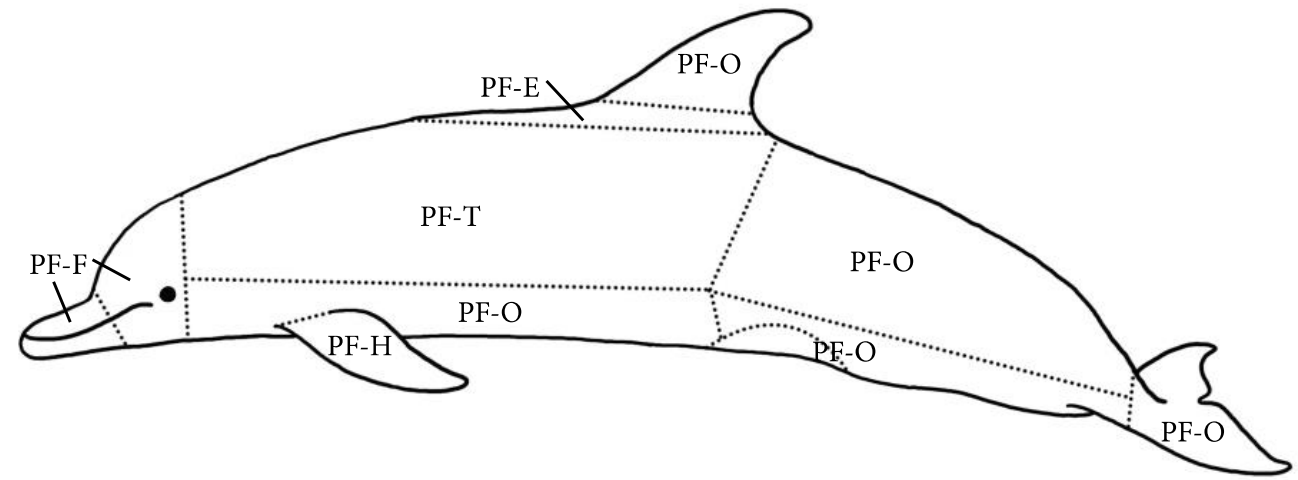

Note. PF-E is a dolphin's back. PF-F is the rostrum, face and melon. PH-H is the pectoral fin. PF-T is the lateral sides. PF-O includes the dorsal fin, belly, genital area, peduncle (dorsal and ventral) and the fluke. Sketch adapted from Dudzinski et al. (2009).

\section{Statistical Analyses}

The sampling unit was the identified initiating or receiving mother for each PFC exchange with her identified calves. Data were collated by mother (Table 2). Note that Table 1 contains all observations of PFC exchange between each adult female and each of her calves regardless of whether the initiator (INI) is known or not. Table 2 contains data for PFC exchanges between adult females and their calves for PFC exchanges only where the INI is known.

Table 2

Total Number of PFC for Adult Females with her Calves, Regardless of Calf Sex and Age, Categorized by the Mother as Initiator and Mother as Receiver (i.e., Calf as Initiator)

\begin{tabular}{lcccc}
\hline & & \multicolumn{2}{c}{ Pectoral Fin Contacts } & \\
\cline { 3 - 4 } \multicolumn{1}{c}{ Mother } & $\begin{array}{c}\text { Number of } \\
\text { calves }\end{array}$ & $\begin{array}{c}\text { Mother as } \\
\text { Initiator }\end{array}$ & $\begin{array}{c}\text { Calf as } \\
\text { Initiator }\end{array}$ & $\begin{array}{c}\text { Total Known } \\
\text { Initiator } \\
\text { interactions }\end{array}$ \\
\hline Gracie & 5 & 36 & 64 & 100 \\
Alita & 4 & 19 & 39 & 58 \\
Mrs. B. & 3 & 6 & 33 & 39 \\
Cedeña & 3 & 16 & 20 & 36 \\
Mika & 2 & 5 & 23 & 28 \\
Bailey & 1 & 16 & 27 & 43 \\
Carmella & 3 & 4 & 5 & 9 \\
Rita & 1 & 3 & 6 & 9 \\
GeeGee & 1 & 1 & 1 & 2 \\
Maury & 1 & 0 & 1 & 1 \\
\hline
\end{tabular}

Note: Number of calves are the number of the mother's calves with whom she interacted. The sample size and number of calves per female in this table can differ from the values in Table 1 because Table 2 includes only PFCs exchanged by confirmed initiators, whether adult female or her calf. 
We first examined how mothers use PFCs with their calves, regardless of age and sex. We considered how mothers use PFCs overall to be a potential metric of maternal style. Specifically, we tested for whether mothers have the same probability of initiating contacts with their calves. We used data only from mothers interacting with multiple calves and where the interactions per calf was greater than 5 . Using data from females that interact frequently with multiple calves gave us a better measure of maternal style (larger number of calves and larger number of interactions per calf) than one based on interactions with a single calf (sample size of 1) or low number of interactions/calf (low precision for probability estimates). To determine if the probability of initiating contact varied by mother, we used a generalized linear mixed effects model (McCullagh \& Nelder, 1989). The response variable was coded as 1 if the mother was the initiator and 0 if the mother was the receiver (i.e., the calf was the initiator). The explanatory variable was mother ID as a fixed effect and we used a binomial error structure. Calf ID was the random effect. There were five females who interacted with multiple calves (i.e., multiple calf mothers; Alita, Cedeña, Gracie, Mika, Mrs. B.; Table 2). For females who only interacted with one calf (i.e., single calf mothers) and who had five or more PFC exchanges with their calf (Bailey, Rita) or who had low number of interactions/calf (Carmella; Table 2), we compared their patterns of initiation to possible maternal styles from the model of the five females. We identified potential maternal styles based on groups of mothers that had significantly different patterns of initiation. Specifically, we used the group average probability of the mother initiating contact to define the theoretical distributions against which to compare the patterns of the single calf mothers. We compared the patterns of the single calf mothers against each of the theoretical distributions using contingency tables and a simulation approach to determine significance of the test statistic; 20,000 simulations were conducted for each test (Rugg, 2003). In these tests, the null hypothesis is that single calf mother patterns follow the theoretical distributions. To control for using the same data in two separate tests, we used a $p$-value of .01 as a Bonferroni correction instead of .05 for significance for each test. Females were then assigned to the group where the null hypothesis was not rejected (i.e., the females' probabilities fit the theoretical distribution).

We next analyzed for differences in how the grouped mothers initiated PFC with younger and older calves, and then with respect to body part preference, posture(s) during exchanges, and duration of contacts. We used younger calves ( $\mathrm{C} 1)$ and older calves $(\mathrm{C} 2$ and $\mathrm{C} 3$ ) because sample sizes in the $\mathrm{C} 3$ age class were too low to allow for statistical examination. It is possible that any differences between these two older calf age classes might add variability in our final results but it was our assumption that potential developmental differences between $\mathrm{C} 2$ and $\mathrm{C} 3$ ages would not significantly impact our examination of younger $(\mathrm{C} 1)$ versus older (C2 and C3) calves.

To determine if mothers in the different groups initiated contact differently by calf age, we fit models to see if there was an overall difference by calf age (i.e., a main effect of calf age) and then if the different groups of mothers had a different pattern of initiation by fitting an interaction between calf age and the group of the mother (i.e., an interaction term). We used generalized linear mixed effects models (McCullagh \& Nelder, 1989). The response variable was coded as 1 if the mother was the initiator and 0 if the mother was the receiver (i.e., the calf was the initiator). Calf ID was a random effect and we used a binomial error structure.

To determine if mothers touched different body parts to initiate contact compared to when they received contact, we fit models to see if there was an overall difference by body part contacted (i.e., a main effect of body part). We included two interaction terms. The first interaction was to see if mothers in the different groups initiated an interaction by touching different body parts. The second interaction was to see if mothers initiated an interaction by touching a different body part depending on the age of the calf. We used a generalized linear mixed effects model (Pinheiro \& Bates, 2009). The response variable was coded as 1 if the mother was the initiator and a 0 if the mother was the receiver (i.e., the calf was the initiator). Calf ID was a random effect and we used a binomial error structure.

Because the PF-O body part category was a mix of specific body parts, we looked within the PF-O body part category to see if mothers started an interaction by touching different body parts that fell within the PF-O category. We fit a model to see if the different groups of mothers had a different pattern of initiation by fitting an interaction between the PF-O body part contacted and the group of the mother. Due to small sample sizes, the random effects models did not converge and therefore we used generalized linear models. 
The response variable was coded as 1 if the mother was the initiator and a 0 if the mother was the receiver (i.e., the calf was the initiator) and we used a binomial error structure.

We determined what postures the mothers assumed when initiating and receiving a contact. We used a generalized linear mixed effects model (Pinheiro \& Bates, 2009) to determine if posture of the mother (the response variable) varied when the mother was the initiator or receiver dolphin, whether the mother was in the different initiator groups, and if the calf was younger or older. Due to small sample sizes in some of the postures used, we used two posture categories, the horizontal (HOR) posture and other postures (all postures except horizontal, including ventral up, tail up, head up, on right side, on left side; Dudzinski et al., 2009). The response variable was coded as 1 if the mother used HOR and a 0 if the mother used any other posture. Specifically, we modeled the probability of the mother using HOR as a function of the role of the mother (initiator or receiver), the initiator group of the mother, and calf age (younger, older), including interactions among the explanatory variables. Calf ID was a random effect and we used a binomial error structure. We used a similar approach for duration of PFC contact. We used a generalized linear mixed effects model (Pinheiro \& Bates, 2009) to determine if duration of PFC (the response variable) was a function of the role of the mother, the initiator group, and calf age, including interactions. Calf ID was a random effect and, because duration of contact is a continuous variable, we used a Gaussian error structure.

To understand maternal differences with calves of different sex, we looked at the adult females who had both male and female calves. Although five matrilines had both male and female calves during this 16year study (Table 1), only three adult females (Alita, Gracie, and Mrs. B.) were observed to exchange PFCs with both their male and female calves at all ages $(\mathrm{C} 1, \mathrm{C} 2, \mathrm{C} 3)$ and thus, these three females were used for analysis. Over the years, Alita interacted with two female and two male calves, Gracie interacted with three female and two male claves, and Mrs. B. with one female and two male calves. We specifically were interested in testing whether the pattern of initiating and receiving depending on the sex of the calf was the same across the mothers. To do this, we used a three-dimensional contingency table analysis with the mothers being considered the third dimension (i.e., the strata). The analysis constructs a pooled table of the pattern of initiation by sex of the calves and then compares the three individual mother's patterns from the expected values based on the pooled table, using a simulation approach (see above) to determine significance of the test statistic. We used residual analyses (see above) to determine differences among the mothers.

We used the statistical package R (version 3.6.2) and used glm to run the generalized linear models and glmer for the mixed effects models. For all tests, we assessed significance at a $p$ of .05, except where indicated above.

\section{Results}

\section{How Mothers Use PFC with Their Calves}

Over 16 years of observation of tactile exchanges within bottlenose dolphin dyads at RIMS, 4,345 PFC were documented between kin $(N=766)$ and non-kin pairs $(N=3,579)$. From the kin-exchanged PFC, 408 PFCs (53\% of PFCs between kin) were within mother/calf dyads. For the five females that interacted with more than one calf (i.e., multiple-calf focal females; Table 2), there were 261 PFC within mother/calf dyads where the identity of both initiator and receiver were confirmed; for the remaining five adult females, there were 64 total PFC within these mother/calf dyads, with 43 from one mother/calf dyad (Table 2). Mothers initiated PFC with their calves at different rates $\left(\mathrm{c}^{2}{ }_{4}=11.6, p=.02\right.$; from data for the five focal females, Table 2). Cedeña initiated the most contacts (.44) followed by Gracie (.36) and Alita (.33) while Mika and Mrs. B. initiated fewer (.18 and .15, respectively) with their calves (Table 2). Gracie (coefficient $=-0.39, S E=0.46, p=.39$ ) and Alita (coefficient $=-0.54, S E=0.66, p=.04$ ) were not different from Cedeña while Mika (coefficient $=-1.34, S E=0.66, p=.04$ ) and Mrs. B. (coefficient $=-$ $1.53, S E=0.61, p=0.01$ ) were, resulting in two groups of mothers (high and low PFC initiators).

The high PFC initiator group had an average probability of initiating PFC contact of .38 and the low PFC initiating group had an average probability of initiating PFC contact of .16. The two single-calf mothers (Bailey, Rita) and Carmella (low number of interactions) were more similar to the high PFC initiator group $\left(\mathrm{c}_{2}^{2}=0.27, p=.98\right)$ than the low PFC initiator group $\left(\mathrm{c}^{2}{ }_{2}=21.8, p<.001\right)$. 


\section{Calf Age}

There was no difference in the probability of initiating PFC contact with calves of different ages between the high and low PFC initiator groups of mothers (Calf Age-Mother Group interaction effect: $\mathrm{c}^{2}{ }_{1}$ $=0.89, p=.34)$. Overall, the probability of the mother initiating PFC contact was the same regardless of the age of the calf (Calf Age main effect: $\mathrm{c}^{2}{ }_{1}=0.77, p=.38$ ).

\section{Body Parts Contacted}

There was no difference in the probability of initiating PFC contact using different body parts between the high and low PFC initiator groups of mothers (Contact-Mother Group interaction term: $c^{2}{ }_{4}=$ $4.85, p=.30$ ). Mothers also initiated a PFC by touching similar body parts regardless of the calf's age (Contact-Calf Age interaction term: $\mathrm{c}^{2}{ }_{4}=7.07, p=.13$ ). Mothers and their calves did not contact different body parts to start an interaction (Contact main effect: $\mathrm{c}^{2}{ }_{4}=0.97, p>.50$ ) (Table 3). Both mothers and calves, regardless of calf age, contacted the lateral side (PF-T) and the group of other parts of the body (PF-O) the most to start interactions (Table 3).

\section{Table 3}

Probability of Starting an Interaction by Touching Specific Body Parts by Mothers and Their Calves

\begin{tabular}{|c|c|c|c|c|c|}
\hline & \multicolumn{5}{|c|}{ Response Probabilities } \\
\hline Population & $\begin{array}{c}\text { The back (PF- } \\
\text { E) }\end{array}$ & $\begin{array}{l}\text { Rostrum, face, and } \\
\text { melon (PF-F) }\end{array}$ & $\begin{array}{c}\text { Pectoral fin (PF- } \\
\mathrm{H})\end{array}$ & $\begin{array}{l}\text { Other parts of the } \\
\text { body }(\mathrm{PF}-\mathrm{O})\end{array}$ & $\begin{array}{l}\text { Lateral side } \\
\quad(\mathrm{PF}-\mathrm{T})\end{array}$ \\
\hline Mother Initiator & .077 & .164 & .067 & .346 & .346 \\
\hline Calves Initiator & .081 & .153 & .076 & .345 & .345 \\
\hline Combined & .079 & .156 & .073 & .346 & .346 \\
\hline
\end{tabular}

Focusing on the body parts within the PF-O category, there was no difference for how mothers in the high and low PFC initiator groups started an interaction when touching a body part in the PF-O category (PF-O Contact-Mother Group Interaction term: $\mathrm{c}^{2}{ }_{4}=7.30, p=.12$ ). In addition, mothers and their calves did not contact different body parts to start PFC contact when starting an interaction touching a body part in the PF-O category (PF-O body part term: $\left.\mathrm{c}^{2}{ }_{5}=8.30, p=.14\right)$. Overall, mothers and calves touched the belly the most followed by the dorsal peduncle, the dorsal fin, and the ventral peduncle while the genital area and fluke were rarely contacted (Table 4).

\section{Table 4}

Frequency of Contacts for Body Parts Included in the PF-O Section from Mother-initiated and Calf-initiated Contacts

\begin{tabular}{|c|c|c|c|c|c|c|c|}
\hline & Dorsal fin & Belly & $\begin{array}{c}\text { Genital } \\
\text { area }\end{array}$ & $\begin{array}{c}\text { Dorsal } \\
\text { peduncle }\end{array}$ & $\begin{array}{c}\text { Ventral } \\
\text { peduncle }\end{array}$ & Fluke & Total PF-O \\
\hline Mother Initiator & 4 & 13 & 0 & 12 & 4 & 3 & 36 \\
\hline Calf Initiator & 15 & 19 & 4 & 17 & 15 & 3 & 73 \\
\hline $\begin{array}{l}\text { All Initiators } \\
\text { (Mother-Calf) }\end{array}$ & 19 & 32 & 4 & 29 & 19 & 6 & 109 \\
\hline Proportions & 0.174 & 0.293 & 0.037 & 0.266 & 0.174 & 0.056 & \\
\hline
\end{tabular}




\section{Postures Used by Mothers}

Mothers in both high and low PFC initiator groups used the horizontal (HOR) position when they initiated or received PFC (Mother role-Mother group interaction term: $\mathrm{c}^{2}{ }_{1}=0.34, p=.56$ ). Mothers also initiated or received PFC using the HOR position regardless of age of calf (Mother role-Calf Age interaction term: $\mathrm{c}^{2}{ }_{1}=0.56, p=.45$ ). The strongest effect was the age of the calf; the use of the HOR position declined when the mothers interacted with their older calves (older calf coefficient $=-1.07, \mathrm{SE}=$ $0.49, p=.03$ ); mothers used the HOR position $68.9 \%$ with the older calves compared to $87.4 \%$ with younger calves (Table 5). Mothers used the HOR posture regardless of role (Mother INI coefficient $=$ $0.53, \mathrm{SE}=0.30, p=.08$ ) and regardless of mother high or low PFC initiator group (Low INI group coefficient $=0.61, S E=0.62, p=.32$ ).

\section{Table 5}

Frequency of Horizontal (HOR) and Other Postures Assumed by Mothers When Initiating and Receiving PFC by Calf Age

\begin{tabular}{|c|c|c|c|c|c|}
\hline & Role & HOR & Other & Proportion (HOR) & Total \\
\hline \multirow[t]{3}{*}{ Initiator } & & 74 & 32 & .698 & 106 \\
\hline & with young calves & 28 & 8 & & 36 \\
\hline & with older calves & 46 & 24 & & 70 \\
\hline \multirow[t]{3}{*}{ Receiver } & & 172 & 47 & .785 & 219 \\
\hline & with young calves & 76 & 7 & & 83 \\
\hline & with older calves & 96 & 40 & & 136 \\
\hline Total & & 246 & 79 & .757 & 325 \\
\hline
\end{tabular}

\section{Contact Durations}

Duration of contact did not differ regardless of whether the mother was the initiator or receiver of a PFC with their calves (mother INI coefficient $=-0.10, S E=0.26, p=.67$ ) nor between the mother high and low PFC initiator groups (mother group coefficient $=-0.06, S E=0.31, p=.75$ ). Contact duration differed with age of the calf with older calves having a shorter duration of contact (older calf age coefficient $=-0.61, S E=0.25, p=.016)$. Average contact duration for mothers and younger calves was 2.3 $\sec (S D=2.8 \mathrm{~s}, N=119$ PFCs $)$. Average contact duration for mothers with older calves was $1.7 \mathrm{~s}(S D=$ $1.7 \mathrm{~s}, N=203$ PFCs).

\section{Differences in PFC Exchanges between Adult Females with Female and Male Calves}

There were differences among the three females (Alita, Gracie, and Mrs. B.) in how they interacted with their female and male calves (regardless of age) $\left(\mathrm{c}^{2}{ }_{2}=32.0, p<.001\right.$; Table 6). Alita had a higher probability of receiving contact from her female calves than from her male calves. Gracie and her calves initiated the same proportion of PFC as expected under the pooled distribution. Mrs. B. had a higher probability of receiving contact from her male calves than from her female calves. 
Table 6

Frequency of Contact for Three Dolphin Mothers and Their Female and Male Calves in the Role of Initiator of Pectoral Fin Contacts

\begin{tabular}{lcccc}
\hline & $\begin{array}{c}\text { Mother initiates with } \\
\text { CF }\end{array}$ & $\begin{array}{c}\text { Mother initiates with } \\
\text { CM }\end{array}$ & CF initiates & CM initiates \\
\hline \multicolumn{1}{c}{$\begin{array}{c}\text { Pooled pattern } \\
\quad \text { Counts }\end{array}$} & 0.17 & 0.14 & 0.38 & 0.31 \\
Alita & 13 & & & 5 \\
Gracie & 18 & 6 & 34 & 35 \\
Mrs. B. & 2 & 18 & 29 & 21 \\
$\quad$ Chi Residuals & 1.05 & 4 & 12 & -3.06 \\
Alita & 0.31 & -0.78 & 2.54 & 0.73 \\
Gracie & -1.77 & 1 & -1.47 & -0.74 \\
Mrs. B. & & -0.66 & & $\mathbf{2 . 5 7}$ \\
\hline
\end{tabular}

Note. $\mathrm{CF}$ is female calf. $\mathrm{CM}$ is male calf. Bold font in the residual tables indicates significance.

\section{Discussion}

Our previous research on pectoral fin contacts (PFC) exchanged between dolphins established that PFC is exchanged at similar overall rates and within same-aged and sexed dyads than mixed-aged and sex pairs regardless of environmental setting (Dudzinski et al., 2009, 2010, 2013). We also found PFC is a tool to establish and maintain social bonds between non-kin male bottlenose dolphins (Dudzinski \& Ribic, 2017). This study extends these findings by examining the functional role of PFC within mother-calf dyads. Overall, only $17.6 \%$ of all documented PFC exchanges were shared between kin, including mother/calf dyads who shared about $9 \%$ of the total PFC exchanges. This quantity of documented PFC is much lower than that found for interactions of unrelated animals (Dudzinski \& Ribic, 2017) and indicates that PFC is primarily used by unrelated dolphins to build and maintain bonds or mitigate social interactions (Dudzinski \& Ribic, 2017).

Even though our sample of PFC exchanges was small for kin and suggestive that other tactile behaviors might be used more frequently within mother/calf dyads, we were able to identify patterns that indicate functional use and maybe developmental (or maturation-related) factors in how PFC are used when shared by these kin. As a calf ages and matures, less time is spent with the mother, which may be directly reflected in decreased durations between mother-calf PFC from the first year to the next two years combined. PFC might be used as a teaching tool (either actively from the mother or passively through observation of the mother by the calf) that provides offspring with the fundamental meaning underlying the different uses of PFC that also could be modified by individual (maternal) style. Krzyszczyk et al. (2017) identified sex differences in social and behavioral development of juvenile bottlenose dolphins; for example, juvenile same-sex social bonds seemed to foreshadow adult patterns and observed increased foraging rates by juvenile females but not males could be related to future energetic demands of gestation and lactation.

Different patterns of initiating PFC were observed for the adult female bottlenose dolphins in this study group. The five multiple-calf mothers initiated PFC differently; three adult females (Gracie, Alita, Cedeña) initiated PFC more than twice as much with their calves as did the other two multiple-calf mothers (Mika and Mrs. B.). Bailey, Carmella, and Rita, the single-calf mothers group, had similar PFC initiation rates with their calves to the high PFC initiator group, which includes Gracie, Alita, and Cedeña. In addition, there is variation in the amount of contact observed between mother-calf dyads with some pairs having few interactions (e.g., Cedeña/Calli, GeeGee/Mika) or none (e.g., Mika/Poli) while others had many (e.g., Alita or Gracie and their calves). These findings support the notion of maternal style for adult female dolphins using PFC as one characteristic used to distinguish different styles (Hill et al., 2007; Mann \& Smuts, 1998). 
In our study, the three adult females (Alita, Gracie, Mrs. B.) that comprised the high PFC initiator group shared contact as initiator and receiver with both female and male calves. Because Gracie and her calves presented the largest sample size of documented PFC, she is driving the common pattern. Thus, our analyses investigated whether Alita and Mrs. B. were more similar to Gracie or not. All three of these females presented different patterns of interaction for their shared PFC with their calves, which further supports the hypothesis that these dolphins have distinct maternal styles (Hill et al., 2007). Gracie shared the most PFC with her calves - both younger and older individuals, though she initiated more with her older calves. Alita received more PFC from her older calves but initiated more with her younger offspring. And, Mrs. B. rarely initiated with her calves, even though she was a very protective and attentive mother, and received more PFC from her younger than older calves.

Even though the other adult females in this study had calves of both sexes, the PFC dataset for these mother/calf dyads represented only one calf sex (e.g., PFC for Mika and Carmella were only with their male calves). We were not able to document each adult female with all of her calves at each pre-weaning age (i.e., $\mathrm{C} 1, \mathrm{C} 2, \mathrm{C} 3)$. This variation in recording may reflect each female's individuality as well as data collection opportunities (i.e., time of year when data were collected versus calf births). Although the dolphin calf personalities in our study group have not been assessed and may not yet have become stable (Highfill \& Kuczaj, 2007), the adult females in this social group have documented distinct personalities (Macgregor, 2018; Moreno et al., 2017), which likely directly contribute to the maternal differences observed in this study. For example, Gracie routinely presented her calves to trainers and observers both at the surface and underwater whereas Carmella and Mrs. B. tended to be more protective and guarded with their calves, hovering in the background even when their older calves were playing with peers. Second, because data were collected in short ( 1 to 3 weeks) field sessions once or twice a year, our observation dates may not have overlapped with some ages for all calves from each adult female (see Limitations and Future Directions section below).

In most mammals, mother-infant interactions are typically measured by spatial proximity (Hinde, 1970), which includes the frequency with which a mother-infant dyad is in contact and who is responsible for this contact (e.g., Japanese monkeys (Macaca fuscata), Schino et al., 1995; macaques (Macaca mulatta), Fairbanks, 1996; bonobos (Pan paniscus) and chimpanzees (Pan troglodytes), DeLathowres \& Eslacker, 2004). Emphasis is placed on describing who initiated the contact and who received it, which is very successful in showing how contact is a variable that plays an important role in differentiating different mother-infant dyads. These distinct patterns of directed PFC (i.e., initiator versus receiver role) by the three adult female dolphins (Alita, Gracie, Mrs. B.) for whom large enough PFC samples were available are similar to documented contacts among chimpanzees in their first few months of life. Chimpanzee infants mostly solicit contact with or from their mothers within their first few months of life (Botero et al., 2013, 2017), with individual differences observed among chimpanzee mothers and also between different infants of the same mother.

Previous PFC research on dolphins identified a body part preference for the rubber and rubbee as initiators (Dudzinski et al., 2010). In this study, mothers contacted calf body parts differentially with the lateral side being the most preferred body part. This tendency may be driven by the observation that horizontal postures were assumed more frequently than all other postures by all observed adult female dolphins when sharing PFC with their calves. However, it is unclear whether the preference for the lateral side is a true preference, especially for the younger calves, or simply an artifact of the echelon swim position (Noren, 2008; Noren et al., 2008), when calves gain hydrodynamic benefits at an energetic cost to the mother (Noren, 2008; Noren \& Edwards, 2011). Other physiological development markers (e.g., breath-holding and stroke rate increases; Noren et al., 2002) also correlate with maturity as a calf approaches independence from the mother; thus, changes in PFC exchanges between mothers and calves associated with calf age would not be unexpected. Use of the echelon swim position decreases as a calf matures and develops musculature that allows for more independent swimming (Gubbins et al., 1999; Xian et al., 2012). A transition to social independence, not only physical maturity, was documented for Indo-Pacific bottlenose dolphins (Tursiops aduncus) as calves aged into juvenility (Krzyszczyk et al., 2017). Mothers (in the role of rubbee with a calf as rubber) in our study also showed more contact with the belly, after the lateral side, which could be associated with the infant swim position (Gubbins et al., 1999). The infant swim position 
places the calf below the mother's genital and mammary gland area. This position also affords energetic swim benefits as well as close proximity to the mammary glands for more efficient nursing. As a calf develops, it shifts from the echelon to the infant swim position with mother (Gubbins et al., 1999; Xian et al., 2012). Thus, for younger calves the two primary body parts contacted could be related to swim position that has other survival benefits for the calf, rather than a selection of body part per se. An alternative is that the calves might simply not yet be discriminatory in their body awareness or selection until they have gained more maturity.

Given the paucity of PFC within mother/calf dyads as compared with PFC shared between non-kin individuals in this study group, it is not likely that contact via the pectoral fin is a behavioral tool used by kin to establish or maintain their relationships, though siblings might share PFC differently compared to how each offspring might share PFC with their mother (Dudzinski et al., in press). Though human researchers might not know how, it is likely that dolphins recognize kin without aid of behavioral contact or overt signal use. Bruck et al. (2013) demonstrated that dolphins possess long-term social memory for conspecifics with whom a strong relationship was once shared. Dolphins possess a large, complex brain that facilitates recognition of the ever-changing relationships within a complex fission-fusion society (Marino et al., 2007). While pectoral fin contact is probably not important within the confines of the mother-calf relationship, other forms of tactile contact (e.g., body-body rubbing) likely are more socially essential to the developing relationships between both kin and non-kin.

\section{Limitations and Future Directions}

These data are part of a longitudinal study to assess dolphin communication, behavior, and social structure among several study populations: data were (and are) collected in a non-invasive manner from the underwater perspective. Data collection was (and is) conducted during short field sessions (observational periods) ranging from one to several weeks in length. Because this study population resides in managed care, we know the birth dates of all individuals born at the facility (75\% of the group). As such, we were able to confirm each calf's age (C1, C2, C3, etc.) during each field session. Two data collection limitations were encountered that affected our observations: 1) not observing some calves at specific ages (i.e., not observing the calf at a given age), and 2) collecting data for each calf's age but not recording any PFC between a mother and calf for a particular calf age. These two limitations are quite different in that the first represented no data possible for a particular calf at a given age category while the second could actually be related to personality or style differences. That is, for the data collection second limitation, observations of the calf at each age were conducted but there were no PFC documented.

While we found maternal differences studying only a small number of mothers, personality may be an important factor explaining why we found these differences. Five-factor personality surveys have been applied to dolphins with results indicating that stable and distinct personalities are present (see Highfill \& Kuczaj, 2007). Even though surveys have been completed for each dolphin in this study population (Macgregor, 2018; Moreno et al., 2017), a comparative discussion of personality differences between individuals has not been formalized. Based on ad libitum and anecdotal reports of approach proximity by training staff and authors of the study, some adult females are considered more shy or aloof while others are more bold or confident. Thus, due to individual differences in approach proximity, we likely have more video data of females and their calves who would be categorized as more confident or bolder as compared to the females who would be rated as shy and aloof. Additionally, as related to potential personality differences, some adult females will be frequent (i.e., high) initiators of shared interaction and behavioral exchange while others will be less likely to initiate contact. These differences between individuals could be related to variation in established dyadic relationships (e.g., Themelin, 2019) or to other factors (e.g., environmental or habitat differences or human-dolphin interactions during swim-with programs). More research is required to better understand maternal differences in other dolphin groups and how these different profiles emerge.

Dolphins use tactile behavior to share a variety of messages depending on the context. Dudzinski et al. (2010) and Dudzinski et al. (2013) confirmed that PFC is a conserved behavior shared between dolphins consistently regardless of the environment (e.g., substrate or habitat). Dudzinski and Ribic (2017) clarified 
that PFC is one tool in the dolphin cognitive box that allows individuals within a dyad to establish and maintain their social relationships. The functional aspects of PFC as a tool to manage dolphin relationships is further supported by the results related to the paucity of PFC exchanges within mother/calf dyads, indeed the overall lack of PFC among kin. Social behavior and developing relationships are mediated by a variety of complex, coordinated signals. The current paper only describes the maternal role in PFC. To understand the development and use of PFC by young dolphins, PFC must also be examined from the calf perspective (Dudzinski et al., in press).

An evaluation of other forms of contact, not only PFC, between mothers and calves will elucidate better the role of tactile contact in a dolphin's life, from neonate through weaning and into adulthood. Touch is a valuable tool that helps mediate social relationships through a variety of functional roles: as an affiliative contact, a disciplinary action, for aggressive intent, and possibly as a learning platform. Future research should continue to examine the role of touch in all animals.

\section{Acknowledgments}

Financial support for longitudinal data collection has been provided continuously by the Dolphin Communication Project (DCP). At the time of publication, the data have not been published by DCP but can be made available for examination. The Galindo Family and Anthony's Key Resort (AKR) provided logistical support that included lodging, food, and access to the dolphins during all years of study at the

Roatan Institute for Marine Sciences (RIMS). DCP-organized eco-tours brought volunteers to AKR to assist with additional funding for data collection. Mystic Aquarium provided financial support towards data collection during 2004-2006. Eldon Bolton, RIMS Director, provided access to records for the dolphins under his supervision. The training team of RIMS provided much insight and discussion during and after observation sessions of the dolphins. Numerous interns and volunteers assisted with processing video data, special thanks to A. Levengood, N. Danaher-Garcia, B. McIntosh, J. Evans-Wilent, W. Greene, and N. Batzel. M. Botero, K. Melillo-Sweeting, J. Gregg, and D. Rugg reviewed early drafts of this manuscript. D. Rugg provided valuable suggestions on statistical analyses. Any use of trade, product, or firm names is for descriptive purposes only and does not imply endorsement by the U.S. Government. This paper represents contribution \#123 of the Dolphin Communication Project.

\section{References}

Botero, M., MacDonald, S., \& Miller, R. (2013). Anxiety-related behavior of orphan chimpanzees (Pan troglodytes schweinfurthii) at Gombe National Park, Tanzania. Primates, 54, 21-26. https://doi.org/10.1007/s10329-0120327-1

Botero, M., MacDonald, S., Shanker, S., Pusey, A., \& Wallauer, B. (2017, April). Effects of mother-infant interaction on anxiety and social behavior of infant chimpanzees (Pan troglodytes schweinfurthii) at Gombe National Park, Tanzania [Paper session presentation]. Annual meeting of the Comparative Cognition Society, Melbourne, FL, United States.

Bruck, J. (2013). Decades-long social memory in bottlenose dolphins. Proceedings of the Royal Society of London B: Biological Sciences, 280, http://doi.org/10.1098/rspb.2013.1726

Connor, R. C. (1992). Dolphin alliances and coalitions. In A. H. Harcourt \& F. de Waal (Eds), Coalitions and alliances in humans and other animals (pp. 415-443). Oxford University Press.

Connor, R. C., \& Krützen, M. (2015). Male dolphin alliances in Shark Bay: Changing perspectives in a 30-year study. Animal Behaviour, 103, 223-235. http://dx.doi.org/10.1016/j.anbehav.2015.02.019

Connor, R. C., Mann, J., \& Watson-Capps, J. (2006). A sex-specific affiliative contact behavior in Indian Ocean bottlenose dolphins, Tursiops sp. Ethology, 112, 631-638. http://doi.org/10.1111/j.1439-0310.2006.01203.x

Connor, R. C., Smolker, R., \& Bejder, L. (2006). Synchrony, social behaviour and alliance affiliation in Indian Ocean bottlenose dolphins, Tursiops aduncus. Animal Behaviour, 72, 1371-1378. http://doi.org/10.1016/j.anbehav.2006.03.014

Connor, R. C., Smolker, R. A., \& Richards, A. F. (1992). Two levels of alliance formation among male bottlenose dolphins (Tursiops sp.). Proceedings of the National Academy of Sciences of the United States of America, 89, 987-990. http://doi.org/10.1073/pnas.89.3.987 
DeLathowres, M., \& Eslacker, L. V. (2004). Comparing maternal styles in bonobos (Pan paniscus) and chimpanzees (Pan troglodytes). American Journal of Primatology, 64, 411-423. http://doi.org/10.1002/ajp.20089

Dudzinski, K. M. (1996). Communication in Atlantic spotted dolphins (Stenella frontalis): Relationships between vocal and behavioral activities [Unpublished doctoral dissertation]. Texas A\&M University.

Dudzinski, K. M. (1998). Contact behavior and signal exchange among Atlantic spotted dolphins (Stenella frontalis). Aquatic Mammals, 24, 129-142.

Dudzinski, K. M., Clark, C. W., \& Würsig, B. (1995). A mobile video/acoustic system for simultaneous recording underwater recording of dolphin interactions. Aquatic Mammals 21, 187-193.

Dudzinski, K. M., Danaher-Garcia, N., \& Gregg, J. D. (2013). Pectoral fin contact between dolphin dyads at Zoo Duisburg, with comparison to other dolphin study populations. Aquatic Mammals, 39, 335-343. http://doi.org/10.1578/AM.39.4.2013.335

Dudzinski, K. M., Gregg, J. D., Melillo-Sweeting, K., Levengood, A., Seay, B., \& Kuczaj II, S. A. (2012). Tactile contact exchanges between dolphins: Self-rubbing versus inter-individual contact in three species from three geographies. International Journal of Comparative Psychology - Special Symposium Issue, 25, 21-43.

Dudzinski, K. M., Gregg, J. D., Paulos, R. D., \& Kuczaj, S. A. (2010). A comparison of pectoral fin contact behaviour for three distinct dolphin populations. Behavioural Processes, 84, 559-567. http://doi.org/10.1016/j.beproc.2010.02.013

Dudzinski, K. M., Gregg, J. D., Ribic, C. A., \& Kuczaj, S. A. (2009). A comparison of pectoral fin contact between two different wild dolphin populations. Behavioural Processes, 80, 182-190. http://doi.org/10.1016/j.beproc.2008.11.001

Dudzinski, K. M., \& Ribic, C. A. (2017). Pectoral fin contact as a mechanism for social bonding among dolphins. Animal Behavior \& Cognition, 4, 31-49. http://doi.org/10.12966/abc.03.02.2017

Dudzinski, K. M., Ribic, C. A., Hill, H. M., \& Bolton, T. T. (in press). Dolphin calf initiated pectoral fin contact exchanges with kin and non-kin. Animal Behavior and Cognition.

Evans-Wilent, J., \& Dudzinski, K. M. (2013). Vocalizations associated with pectoral fin contact in bottlenose dolphins (Tursiops truncatus). Behavioural Processes, 100, 74-81. http://dx.doi.org/10.1016/j.beproc.2013.07.025

Fairbanks, L. A. (1996). Individual differences in maternal style: Causes and consequences for mothers and offspring. Advances in the Study of Behavior, 25, 579-611. https://doi.org/10.1016/S0065-3454(08)60343-5

Gibson, Q. A., \& Mann, J. (2008). Early social development in wild bottlenose dolphins: Sex differences, individual variation and maternal influences. Animal Behaviour, 76, 375-387. http://doi.org/10.1016/j.anbehav.2008.01.021

Greene, W., Melillo-Sweeting, K., \& Dudzinski, K. M. (2011). Comparing object play in captive and wild dolphins. International Journal of Comparative Psychology, 24, 292-306.

Gubbins, C., McCowan, B., Lynn, S. K., Hooper, S., \& Reiss, D. (1999). Mother-infant spatial relations in captive bottlenose dolphins, Tursiops truncatus. Marine Mammal Science, 15, 751-765. https://doi.org/10.1111/j.1748-7692.1999.tb00841.x

Harvey, B. S., Dudzinski, K. M., \& Kuczaj, S. A. (2017). The nature of social relationships in bottlenose dolphins (Tursiops truncatus): Associations and the role of affiliative, agonistic, and socio-sexual behaviors. Behavioural Processes, 135, 145-156. http://dx.doi.org/10.1016/j.beproc.2016.12.013

Highfill, L., \& Kuczaj, S. (2007). Do bottlenose dolphins (Tursiops truncatus) have distinct and stable personalities? Aquatic Mammals, 33, 380-389. http://doi.org/10.1578/AM.33.3.2007.380

Hill, H. M. (2009). The behavioral development of two beluga calves during the first year of life. International Journal of Comparative Psychology, 22, 234-253.

Hill, H. M., Campbell, C., Dalton, L., \& Osborn, S. (2013). The first year of behavioral development and maternal care of beluga (Delphinapterus leucas) calves in human care. Zoo Biology, 32, 565-570. http://doi.org/10.1002/zoo.21093

Hill, H. M., Carder, D., \& Ridgway, S. (2008). Vigilance in female bottlenose dolphins (Tursiops spp) before and after calving. International Journal of Comparative Psychology, 21, 35-57.

Hill, H., Dietrich, S., Jantea, R. F., Garza, S., \& Lacy, K. (2018). The frequency of contact in beluga (Delphinapterus leucas) calf social interactions. Aquatic Mammals, 44, 62-75. http://doi.org/10.1578/AM.44.1.2018.62

Hill, H. M., Greer, T., Solangi, M., \& Kuczaj, S.A. II. (2007). Evidence for maternal styles in captive bottlenose dolphins. International Journal of Comparative Psychology, 20, 34-53.

Hinde, R. A. (1970). Animal behavior (2 $2^{\text {nd }}$ ed.). McGraw-Hill.

Kogi, K., Hishi, T., Imamura, A., Iwatani, T., \& Dudzinski, K.M. (2004). Demographic parameters of Indo-Pacific bottlenose dolphins (Tursiops aduncus) around Mikura Island, Japan. Marine Mammal Science, 20, 510-526. 
Krzyszczyk, E., Patterson, E. M., Stanton, M. A., \& Mann, J. (2017). The transition to independence: Sex differences in social and behavioural development of wild bottlenose dolphins. Animal Behaviour, 129, 43-59. http://dx.doi.org/10.1016/j.anbehav.2017.04.011

Kuczaj, S. A., \& Eskelinen, H. C. 2014. Why do dolphins play? Animal Behavior \& Cognition, 1, 113-127. http://doi.org/10.12966/abc.05.03.2014

Lusseau, D. (2003). The emergent properties of a dolphin social network. Proceedings of the Royal Society of London B (Biology Letters) 03BL0149.S1-S3. http://doi.org/10.1098/rsbl.2003.0057

Lusseau, D., Wilson, B., Hammond, P. S., Grellier, K., Durban, J. W., Parsons, K. M., Barton, T. R., \& Thompson, P. A. (2006). Quantifying the influence of sociality on population structure in bottlenose dolphins. Journal of Animal Ecology, 75, 14-24. http://doi.org/10.1111/j.1365-2656.2005.01013.x

Lyamin, O. I., Manger, P. R., Ridgway, S. H., Mukhametov, L. M., \& Siegel, J. M. (2008). Cetacean sleep: An unusual form of mammalian sleep. Neuroscience and Biobehavioral Reviews, 32, 1451-1484. https://doi.org/10.1016/j.neubiorev.2008.05.023

Lyamin, O., Pryaslova, J., Kosenko, P., \& Siegel, J. (2007). Behavioral aspects of sleep in bottlenose dolphin mothers and their calves. Physiology \& Behavior, 92, 725-733. http://10.1016/j.physbeh.2007.05.064

Lyamin, O., Pryaslova, J., Lance, V., \& Siegel, J. (2005). Animal behaviour: Continuous activity in cetaceans after birth. Nature, 435, 1177. https://doi.org/10.1038/nature04898

Macgregor, R. P. (2018). Using personality traits to predict pectoral fin contact initiation role in bottlenose dolphins (Tursiops truncatus) [Unpublished master's Thesis]. University of Southern Mississippi.

Mann, J. (1999). Behavioral sampling for cetaceans: A review and critique. Marine Mammal Science, 15, 102-122. https://doi.org/10.1111/j.1748-7692.1999.tb00784.x

Mann, J., \& Smuts, B. B. (1998). Natal attraction: Allomaternal care and mother-infant separations in wild bottlenose dolphins. Animal Behaviour, 55, 1097-1113. https://doi:10.1006/anbe.1997.0637

Mann, J. \& Smuts, B. (1999). Behavioral development in wild bottlenose dolphin newborns (Tursiops sp.). Behaviour, 136, 529-566. https://doi.org/10.1163/156853999501469

Mann, J., Connor, R. C., Barre, L. M., \& Heithaus, M. R. (2000). Female reproductive success in bottlenose dolphins (Tursiops sp.): Life history, habitat, provisioning, and group-size effects. Behavioral Ecology, 11, 210-219. https://doi.org/10.1093/beheco/11.2.210

Mann, J., Sargeant, B. L., \& Minor, M. (2007). Calf inspections of fish catches in bottlenose dolphins (Tursiops sp.): Evidence for oblique social learning? Marine Mammal Science, 23, 197-202. http://doi.org/10.1111/j.17487692.2006.00087.x

Marino, L., Connor, R. C., Fordyce, R. E., Herman, L. M., Hof, P. R., Lefebvre, L., Lusseau, D., McCowan, B., Nimchinsky, E., A., Pack, A. A., Rendell, L., Reidenberg, J. S., Reiss, D. Uhen, M. D., Van der Gucht, E., \& Whitehead, H. (2007). Cetaceans have complex brains for complex cognition. PLoS Biology, 5, e139. https://doi:10.1371/journal.pbio.0050139

McCullagh, P., \& Nelder, J.A. (1989). Generalized linear models ( $2^{\text {nd }}$ ed.). Chapman and Hall.

Moreno, K. R., Highfill, L., \& Kuczaj II, S. A. (2017). Does personality similarity in bottlenose dolphin pairs influence dyadic bond characteristics? International Journal of Comparative Psychology, 30. http://escholarship.org/uc/item/1b38j9s2

Noren, S. R. (2008). Infant carrying behaviour in dolphins: Costly parental care in an aquatic environment. Functional Ecology, 22, 284-288. http://doi.org/10.1111/j.1365-2435.2007.01354.x

Noren, S. R., Biedenbach, G., Redfern, J. V., \& Edwards, E. F. (2008). Hitching a ride: The formation locomotion strategy of dolphin calves. Functional Ecology, 22, 278-283. http:///doi.org/10.1111/j.13652435.2007.01353.x

Noren, S. R., \& Edwards, E. F. (2011). Infant position in mother-calf dolphin pairs: Formation locomotion with hydrodynamic benefits. Marine Ecology Progress Series, 424, 229-236. http:///doi.org/10.3354/meps08986

Noren, S. R., Lacave, G., Wells, R. S., \& Williams, T. M. (2002). The development of blood oxygen stores in bottlenose dolphins (Tursiops truncatus): Implications for diving capacity. Journal of Zoology, 258, 105-113. http://doi.org/10.1017/S0952836902001243

Paulos, R. D., Dudzinski, K., \& Kuczaj, S. (2007). The role of touch in select social interactions of Atlantic spotted dolphin (Stenella frontalis) and Indo-Pacific bottlenose dolphin (Tursiops aduncus). Journal of Ethology, 26, 153-164. http://doi.org/10.1007/s10164-007-0047-y

Paulos, R. D., Trone, M., \& Kuczaj, II, \& S. A. (2010). Play in wild and captive cetaceans. International Journal of Comparative Psychology, 23, 701-722.

Pinheiro, J. C., \& Bates, D. M. (2009). Mixed-effects models in S and S-Plus. Springer. 
Rugg, D. J. (2003). TableSim-A program for analysis of small-sample categorical data. Gen. Tech. Rep. NC-232. U.S. Department of Agriculture, Forest Service, North Central Research Station, St. Paul, MN

Sargeant, B., \& Mann, J. (2009). Developmental evidence for foraging traditions in wild bottlenose dolphins. Animal Behaviour, 78, 715-721. http://doi.org/10.1016/j.anbehav.2009.05.037

Schino, G., D'Amato, F. R., \& Troisi, A. (1995). Mother-infant relationships in Japanese macaques: Sources of interindividual variation. Animal Behaviour, 49, 151-158. https://doi.org/10.1016/0003-3472(95)80162-6

Smolker, R. A., Richards, A. F., Connor, R. C., \& Pepper, J. W. (1992). Sex differences in patterns of association among Indian Ocean bottlenose dolphins. Behaviour, 23, 38-69. https://doi.org/10.1163/156853992X00101

Stanton, M. A., \& Mann, J. (2012). Early social networks predict survival in wild bottlenose dolphins. PLoS One, 7 , 47508. http://doi.org/10.1371/journal.pone.0047508

Tamaki, N., Morisaka, T., \& Taki, M. (2006). Does body contact contribute towards repairing relationships? The association between flipper-rubbing and aggressive behavior in captive bottlenose dolphins. Behavioral Processes, 73, 209-215. http://doi.org/10.1016/j.beproc.2006.05.010

Themelin, M. (2019). New approach for relationship quality study in dolphins [Unpublished masters thesis]. Université Paris 13.

Weaver, A. (2003). Conflict and reconciliation in captive bottlenose dolphins, Tursiops truncatus. Marine Mammal Science, 19, 836-846. https://doi.org/10.1111/j.1748-7692.2003.tb01134.x

Wells, R. S., Scott, M. D., \& Irvine, A. B. (1987). The social structure of free-ranging bottlenose dolphins. In H. H. Genoways (Ed.), Current mammalogy, Vol. 1 (pp. 247-305). Plenum Press.

Xian, Y., Wang, K., Jiang, W., Zheng, B., \& Wang, D. (2012). The development of spatial positions between mother and calf of Yangtze finless porpoises (Neophocaena asiaeorientalis asiaeorientalis) maintained in captive and seminatural environments. Aquatic Mammals, 38, 127-135. http://doi.org/10.1578/AM.38.2.2012.127 


\section{Appendix}

Effort, population demographics, and pectoral fin contacts documented per year of data collection at RIMS, AKR, on Roatan, Honduras. Data summarized for 2003-2013, with data details available in Dudzinski and Ribic (2017). Abbreviations include $\mathrm{F}=$ female, $\mathrm{M}=$ male, $\mathrm{A}=$ adult, $\mathrm{S}=$ subadult, $\mathrm{J}=$ juvenile, $\mathrm{C}=$ calf. Sessions ranged from one week $(2006-2011,2013-2015)$, two weeks (2016), and a mix of one- and two-week sessions (2017-2018).

\begin{tabular}{|c|c|c|c|c|c|}
\hline Year & Effort (min.) & $\begin{array}{l}\text { Group } \\
(\mathrm{N})\end{array}$ & $\mathrm{F}: \mathrm{M}$ & $\begin{array}{l}\text { F: A, S, J, C } \\
\text { M: A, S, J, C }\end{array}$ & Pectoral Fin Contact $(\mathrm{N})$ \\
\hline 2003-2013 & 6,494 & $16-26$ & \multicolumn{2}{|c|}{ See Dudzinski \& Ribic (2017) for details. } & 3,022 \\
\hline 2014 & 115 & 22 & $12: 10$ & $\begin{array}{l}\mathrm{F}: 8,0,2,2 \\
\mathrm{M}: 6,1,0,3\end{array}$ & 76 \\
\hline 2015 & 335 & 20 & $10: 10$ & $\begin{array}{l}\mathrm{F}: 6,0,4,0 \\
\mathrm{M}: 7,0,2,1\end{array}$ & 284 \\
\hline 2016 & 324 & 23 & $11: 12$ & $\begin{array}{l}\mathrm{F}: 6,0,4,0 / 1^{*} \\
\mathrm{M}: 7,0,2 / 3^{*}, 3 / 2^{*}\end{array}$ & 255 \\
\hline 2017 & 482 & 22 & $11: 11$ & $\begin{array}{l}\mathrm{F}: 6 / 7^{*}, 2 / 3^{*}, 2 / 0^{*}, 1 \\
\mathrm{M}: 7 / 6^{*}, 0,3 / 2^{*}, 2 / 3^{*}\end{array}$ & 382 \\
\hline 2018 & 649 & 20 & $11: 9$ & $\begin{array}{c}\text { F: } 7,3,0,1 \\
M: 5 / 4,2,0,2\end{array}$ & 326 \\
\hline Totals: & 8,399 & $16-26$ & & & 4,345 \\
\hline
\end{tabular}

Note. * indicates that one or two dolphins were different ages between sessions within one year. 